\title{
ANALISIS PENGELOLAAN DAN KONTRIBUSI PENERIMAAN RETRIBUSI PELAYANAN KESEHATAN TERHADAP PENDAPATAN ASLI DAERAH DI KABUPATEN MINAHASA UTARA
}

\author{
Brigita R. Umbas ${ }^{1}$, Grace B. Nangoi ${ }^{2}$, Victorina Tirayoh $^{3}$ \\ 1,2,3 Jurusan Akuntansi, Fakultas Ekonomi dan Bisnis, Universitas Sam Ratulangi, J1.Kampus Bahu, Manado, \\ 95115, Indonesia \\ E-mail : brigitaumbas.br@gmail.com
}

\begin{abstract}
Health service levies are contributions to forced governments and direct return services can be appointed.This study has the aim of analyzing the management and contribution of receipts of health service fees by using a qualitative approach from secondary data available in the Regional Revenue Service of North Minahasa Regency. From the results of the study it can be seen that the role, structure and development of North Minahasa District Health Service Levy in an effort to increase local revenue by 107\% in 2017. In 2014 its contribution was only $1.47 \%$ and increased in 2017 to be more effective at 10\%

Keywords: Regional Original Revenue, Health Service Retribution, Effectiveness and Contribution
\end{abstract}

\section{PENDAHULUAN}

Berdasarkan undang-undang tentang keuangan negara, kekuasaan atas pengelolaan kekayaan negara yang dipisahkan dilaksanakan oleh wakil pemerintah dalam kepemilikan kekayaan negara yang dipisahkan yaitu dikuasakan kepada Menteri Keuangan. Untuk meningkatkan pemberian pelayanan kesehatan kepada masyarakat diperlukan penyelenggaraan pelayanan kesehatan yang memadai dan mampu menjangkau segenap komponen masyarakat sesuai dengan kemampuan ekonominya, dan penyediaan sumbersumber pendapatan asli daerah yang hasilnya memadai.

\section{TINJAUAN PUSTAKA}

Pendapatan Asli Daerah (PAD)

Pengertian. Menurut Warsito (2001:128) Pendapatan Asli Daerah "Pendapatan asli daerah (PAD) adalah pendapatan yang bersumber dan dipungut sendiri oleh pemerintah daerah. Sumber PAD terdiri dari: pajak daerah, restribusi daerah, laba dari badan usaha milik daerah (BUMD), dan pendapatan asli daerah lainnya yang sah".

\section{Sumber-Sumber Pendapatan Asli Daerah (PAD)}

1. Hasil Pajak Daerah

2. Hasil retribusi daerah

3. Hasil pengelolaan kekayaan daerah yang dipisahkan

Retribusi Daerah. Retribusi Daerah adalah pungutan daerah sebagai pembayaran atas jasa atau pemberian izin tertentu yang khusus disediakan dan atau diberikan oleh pemerintah daerah untuk kepentingan orang pribadi atau badan.

\section{Ciri-Ciri, Tujuan dan Sifat-Sifat Retribusi Daerah}

Ciri-ciri retribusi daerah :

1. Dipungut oleh pemerintah daerah

2. Pemungutannya bersifat memaksa secara ekonomis

3. Terdapat kontraprestasi secara langsung 
Tujuan Retribusi Daerah. Tujuan yang paling utama adalah untuk mengisi kas negara atau kas daerah guna memenuhi kebutuhan rutinnya.

Sifat-sifat Retribusi Daerah

1. Retribusi yang sifatnya umum.

2. Retribusi yang pungutannya bertujuan.

Objek Retribusi Daerah. Objek retribusi adalah jasa yang diberikan oleh pemerintah daerah kepada orang pribadi/badan.

Subjek Retribusi Daerah

1. Subyek retribusi jasa umum: orang atau pihak yang menggunakan dan menikmati pelayanan jasa umum yang bersangkutan.

2. Subjek Retribusi Jasa Usaha: orang atau pihak yang menggunakan atau menikmati pelayanan jasa usaha yang disediakan.

3. Subjek Retribusi Perizinan Tertentu : orang pribadi pihak yang memperoleh izin tertentu dari pemerintah daerah.

Jenis-jenis Retribusi Daerah. Menurut Undang-Undang No. 28 Tahun 2009 tentang pajak daeah dan retribusi daerah ada tiga yaitu : 1. Retribusi jasa umum. 2. Retribusi jasa usaha. 3. Retribusi perizinan tertentu.

Tata Cara Pemungutan Retribusi Daerah. Proses pemungutan retribusi daerah dilakukan dengan sangat selektif, pemerintah daerah menugaskan petugas untuk pergi kerumah-rumah sakit dan puskesmas yang ada di daerah itu dengan menggunakan SKRD dan dengan proses yang telah ditentukan pemerintah tersebut.

Tata Cara Perhitungan Retribusi Daerah. Undang- Undang No 28 Tahun 2009 tentang Pajak Daerah dan Retribusi Daerah Bagian Keenam Pasal 151 tentang Tata Cara Perhitungan Retribusi.

Tata Cara Penagihan Retribusi Daerah. Penagihan retribusi daerah selama tujuh hari setelah jatuh tempo. Dengan surat teguran penyetoran dikeluarkan oleh pejabat yang ditunjuk.

Tata Cara Penyetoran Retribusi Daerah. Bank Penerima memberikan data transaksi tersebut kepada SIPKD secara online. Bank Penerima membubuhkan tanda tangan/paraf pejabat bank, cap dari bank pada SKRD sebagai bukti pembayaran.

\section{Efektivitas}

Realisasi retribusi pelayanan kesehatan X $100 \%$

Target retribusi pelayanan kesehatan

Konsep Kontribusi. Kontribusi adalah suatu bentuk sumbangan berupa material (uang) atau sumbangan. yang yang bersifat kolektif dalam pembangunan masyarakat.

Jumlah retribusi pelayanan kesehatan X 100\%

Jumlah PAD

\section{METODE PENELITIAN}

Jenis Penelitian. Penelitian ini termasuk jenis penelitian kualitatif. Bila ditinjau dari tujuan dan sifatnya penelitian ini bersifat deskriptif dan cenderung menggunakan analisis.

Tempat dan Waktu Penelitian. Penelitian ini dilakukan pada Kantor Dinas Pendapatan Asli Daerah Kabupaten Minahasa Utara J1. Raya Sukur, Airmadidi, Kabupaten Minahasa Utara, Sulawesi Utara. Waktu penelitian dimulai dari bulan Mei tahun 2018 hingga selesai penelitian ini.

Jenis data, Sumber data, dan Metode Pengumpulan Data

Jenis Data

1. Data Kualitatif. Penelitian ini menggunakan data kualitatif meliputi seluruh informasi yang diperoleh dari hasil wawancara dengan subyek penelitian yaitu staf pegawai kantor 
di bagian pengelolaan retribusi pelayanan kesehatan terkait pengelolaan penerimaan retribusi pelayanan kesehatan di bagian accounting terkait realisasi anggaran untuk peningkatan pendapatan asli daerah di Kabupaten Minahasa.

2. Data Kuantitatif. Dalam penelitian ini data kuantitatifnya adalah data realisasi anggaran penerimaan retribusi pelayanan kesehatan di Kabupaten Minahasa Utara mulai dari tahun 2014-2017. Data berbentuk angka-angka yang dapat dihitung.

Sumber Data. Yang digunakan adalah sumber data primer. Dalam penelitian ini sumber data primer peroleh langsung dari subjek penelitian dengan wawancara terkait pengelolaan penerimaan retribusi pelayanan kesehatan dan penerimaan realisasi anggaran retribusi pelayanan kesehatan dalam empat tahun terakhir yaitu tahun 2014 s/d tahun 2017 di Kabupaten Minahasa Utara. Sehingga data tersebut akan dikumpulkan, dianalisis dan di kelolah lebih lanjut melalui pengamatan langsung berupa catatan hasil wawancara dengan pegawai di Badan Keuangan Kabupaten Minahasa Utara.

\section{Metode Pengumpulan Data}

Wawancara. Penulis melontarkan pertanyaan-pertanyaan langsung kepada narasumber untuk memperoleh data tentang gambaran umum, pengelolaan penerimaan retribusi pelayanan kesehatan dan realisasi penerimaan retribusi pelayanan kesehatan di Kantor Badan Pengelola Pajak dan Retribusi Daerah Kabupaten Minahasa Utara sesuai dengan tujuan penelitian.

Dokumentasi. Peneliti mengumpulkan data berupa dokumen-dokumen, catatancatatan dan arsip realisasi penerimaan retribusi pelayanan kesehatan yang di dapatkan dari pegawai Kantor Badan Keuangan Daerah Kabupaten Minahasa Utara.

Metode dan Proses Analisis. Metode analisis data yang digunakan adalah deskriptif. Langkah-langkah yang dilakukan oleh peneliti dalam proses analisis :

1. Melakukan wawancara.

2. Mendeskripsikan mengenai hasil wawancara tentang pengelolaan penerimaan retribusi pelayanan kesehatan.

3. Mendeskripsikan realisasi anggaran penerimaan retribusi pelayanan kesehatan tahun 2014- 2017.

4. Pengambilan keputusan.

\section{HASIL PENELITIAN DAN PEMBAHASAN}

\subsection{Gambaran Umum Objek Penelitian}

Visi Badan Keuangan Kabupaten Minahasa Utara yaitu "Terwujudnya Pengelolaan Keuangan serta penataan Aset yang Akuntabel dan Transparansi." Badan Keuangan yang merupakan bagian dari Pemerintah Kabupaten Minahasa Utara wajib menyusun rencana strategis SKPD 5 Tahun tahunan dan rencana kerja SKPD tahunan dengan mengacu pada Visi Pemerintah Kabupaten Minahasa Utara yaitu "Minahasa Utara menjadi Kabupaten Agribisnis, Industri dan Pariwisata secara terpatu serta berkelanjutan di tahun 2021".

Tarif Retribusi Pelayanan Kesehatan. Berdasarkan data yang di berikan oleh ibu Pretty Ngantung, tarif retribusi pelayanan kesehatan yang dipakai di Kabupaten Minahasa Utara saat ini sesuai dengan PERDA Provinsi Sulawesi Utara Nomor 2 tahun 2012 tentang retribusi pelayanan kesehatan pada rumah sakit di Kabupaten Minahasa Utara.

Tingkat Perkembangan Penerimaan Pendapatan Asli Daerah di Kabupaten Minahasa Utara. 
Tabel 1. Target Pendapatan Asli Daerah dan Realisasi Pendapatan Asli Daerah Kabupaten Minahasa Utara Tahun 2014-2017

\begin{tabular}{cccr}
\hline Tahun & $\begin{array}{c}\text { Target } \\
\text { (Rupiah) }\end{array}$ & $\begin{array}{l}\text { Realisasi } \\
\text { (Rupiah) }\end{array}$ & Presentase (\%) \\
\hline 2014 & 67.195 .700 .000 & 73.201 .633 .400 & 108,9 \\
2015 & 69.078 .270 .730 & 79.804 .631 .784 & 115,5 \\
2016 & 74.809 .740 .000 & 82.884 .711 .800 & 110,8 \\
2017 & 80.059 .494 .398 & 87.741 .944 .820 & 109,6 \\
\hline
\end{tabular}

Sumber : BP2RD Kabupaten Minahasa Utara (data olahan)

Dari Tabel 1 di atas dapat dilihat Pendapatan Asli Daerah di Kabupaten Minahasa dari tahun 2014 sampai tahun 2017 rata-rata tingkat penerimaan Pendapatan Asli Daerah mencapai target. Mulai dari tahun 2014 mencapai 108,9\% dari target yang ada. Pencapaian tertinggi yaitu pada tahun 2015 sebesar $115,5 \%$ dari target yang ada.

\section{Target dan Realisasi Retribusi Pelayanan Kesehatan Tahun 2014-2017}

Tabel 2. Target Retribusi Pelayanan Kesehatan dan Realisasi Retribusi Pelayanan Kesehatan Kabupaten Minahasa Utara Tahun 2014-2017

\begin{tabular}{ccc}
\hline Tahun & $\begin{array}{c}\text { Target } \\
\text { (Rupiah) }\end{array}$ & $\begin{array}{c}\text { Realisasi } \\
\text { (Rupiah) }\end{array}$ \\
\hline 2014 & 3.300 .148 .000 & 990.859 .268 \\
2015 & 2.150 .000 .000 & 2.376 .468 .604 \\
2016 & 4.350 .000 .000 & 4.645 .629 .902 \\
2017 & 7.500 .000 .000 & 8.006 .579 .600 \\
\hline
\end{tabular}

Sumber : BP2RD Kabupaten Minahasa Utara (data olahan)

Penerimaan retribusi pelayanan kesehatan di Kabupaten Minahasa Utara mengalami penurunan dan peningkatan setiap tahunnya. Ada yang belum mencapai target bahkan ada yang melampaui target. Mulai dari tahun 2014 yang target retribusi sebesar Rp.3.300.148.00 dan realisasi sebesar Rp.990.859.268. Tahun 2015 targetnya sebesar Rp.2.150.000.000 dan realisasinya Rp.2.376.468.604. Mulai meningkat di tahun 2016 sampai tahun 2017 yaitu mencapai Rp.7.500.000.000 untuk target dan realisasinya Rp.8.006.579.600 itu artinya berhasil mencapai target. Sumber retribusi pelayanan kesehatan yang dimaksud adalah seluruh pungutan retribusi pelayanan kesehatan yang berasal dari RSUD Walanda Maramis Airmadidi Kabupaten Minahasa Utara. Kenaikan dan penurunan realisasi penerimaan retribusi pelayanan kesehatan ini tidak luput dari berbagai faktor-faktor yang menghambat maupun mendukung pencapaian target yang ada. 
Tabel 3. Efektivitas Pelayanan Kesehatan Kabupaten Minahasa Utara

Tahun 2014-2017

\begin{tabular}{ccccc}
\hline Tahun & $\begin{array}{c}\text { Target } \\
\text { (Rupiah) }\end{array}$ & $\begin{array}{c}\text { Realisasi } \\
\text { (Rupiah) }\end{array}$ & $\begin{array}{c}\text { Tingkat } \\
\text { efektifitas } \\
(\boldsymbol{\%})\end{array}$ & Keterangan \\
\hline 2014 & 3.300 .148 .000 & 990.859 .268 & 30 & Tidak efektif \\
2015 & 2.150 .000 .000 & 2.376 .468 .604 & 110,53 & Sangat efektif \\
2016 & 4.350 .000 .000 & 4.645 .629 .902 & 107 & Sangat efektif \\
2017 & 7.500 .000 .000 & 8.006 .579 .600 & 107 & Sangat efektif \\
\hline
\end{tabular}

Sumber : Data diolah

Tabel 4. Kontribusi Retribusi Pelayanan Kesehatan Terhadap Pendapatan Asli Daerah Kabupaten Minahasa Utara

\begin{tabular}{ccccl}
\hline Tahun & $\begin{array}{c}\text { Realisasi } \\
\text { Pendapatan } \\
\text { Asli Daerah } \\
(\mathbf{R p})\end{array}$ & $\begin{array}{c}\text { Realisasi } \\
\text { retribusi } \\
\text { pelayanan } \\
\text { kesehatan }(\mathbf{R p})\end{array}$ & $\begin{array}{c}\text { Tingkat } \\
\text { kontribusi } \\
(\boldsymbol{\%})\end{array}$ & Keterangan \\
\hline 2014 & 73.201 .633 .400 & 990.859 .268 & 1,47 & Sangat kurang \\
2015 & 79.804 .631 .784$. & 2.376 .468 .604 & 3,44 & Sangat kurang \\
2016 & 82.884 .711 .800 & 4.645 .629 .902 & 6,22 & Sangat kurang \\
2017 & 87.741 .944 .820 & 8.006 .579 .600 & 10 & Sangat kurang \\
\hline
\end{tabular}

Sumber :Data diolah

Dari Tabel 4 di atas kontribusi retribusi pelayanan kesehatan terhadap PAD Kabupaten Minahasa Utara mulai tahun 2014 sampai tahun 2017 mengalami peningkatan. Dimana tahun 2014 kontribusi retribusi pelayanan kesehatan sebesar 0,013\%. Kemudian di tahun 2015 meningkat menjadi $0,029 \%$. Pada tahun 2016 kontribusi retribusi pelayanan kesehatan meningkat lagi sebesar $0,056 \%$ dan di tahun 2017 mengalami peningkatan sebesar $0,071 \%$.

\subsection{Pembahasan}

Efektivitas Penerimaan Retribusi Pelayanan Kesehatan. Efektivitas retribusi pelayanan kesehatan pada tahun 2014 sebesar 30\%. Pada tahun 2015 meningkat sebesar 110,53\%. Tahun 2016 kembali menurun menjadi 107\% (sangat efektif). Hingga tahun 2017 masih sama tingkat efektivitas yaitu sebesar 107\% (sangat efektif). Tingkat efektivitas tahun 2015 merupakan tingkat efektivitas tertinggi selama kurun waktu 2014-2017. Jika dilihat dari jumlah rata-rata dari tahun 2014-2017 adalah sebesar 88,5 \% yang menunjukkan retribusi pelayanan kesehatan tahun 2014-2017 cukup efektif.

Kontribusi Retribusi Pelayanan Kesehatan Terhadap Pendapatan Asli Daerah Kabupaten Minahasa Utara. Kontribusi retribusi pelayanan kesehatan terhadap PAD Kabupaten Minahasa Utara mulai tahun 2014 sampai tahun 2017 mengalami peningkatan. Dimana tahun 2014 kontribusi retribusi pelayanan kesehatan 0,013\%. Kemudian di tahun 2015 meningkat menjadi $0,029 \%$. Pada tahun 2016 kontribusi retribusi pelayanan kesehatan meningkat lagi yaitu 0,056\% dan di tahun 2017 mengalami peningkatan hingga 0,071\% .

Pengelolaan Penerimaan Retribusi Pelayanan Kesehatan. Pengelolaan penerimaan retribusi pelayanan kesehatan terdiri atas : tata cara pemungutan retribusi pelayanan kesehatan, tata cara perhitungan retribusi pelayanan kesehatan dan tata cara penyetoran retribusi pelayanan kesehatan. 
Tata Cara Pemungutan Retribusi Pelayanan Kesehatan. Dari hasil wawancara, sekretaris Badan Keuangan Daerah menginformasikan bahwa: "Retribusi pelayanan kesehatan di pungut dengan menggunakan Surat Ketetapan Retribusi Daerah atau dokumen lain yang di persamakan. SKRD adalah surat ketetapan retribusi yang menentukan besarnya pokok retribusi. Dokumen lain yang dipersamakan antara lain, berupa karcis masuk, kupon dan kartu langganan. Jadi SKRD diberikan kepada pihak rumah sakit dan puskesmas pada akhir bulan. Dan di setiap bulannya ditagi oleh petugas retribusi pelayanan kesehatan pemerintah Kabupaten Minahasa Utara. Retribusi pelayanan kesehatan yang dipungut harus sesuai dengan fasilitas atau pemanfaatan yang di pakai, jadi pada SKRD dilampirkan surat keterangan yang berisi jenis pelayanan beserta tarifnya yang kemudian akan dihitung oleh petugas retribusi pemerintah daerah" (Responden 2, Sekretaris Bagian Accounting Badan Keuangan Kabupaten Minahasa Utara).

Tata Cara Perhitungan Retribusi Pelayanan Kesehatan. Seperti informasi yang diperoleh penulis dalam wawancara terhadap Sekretaris Bidang Accounting Badan Keuangan Kabupaten Minahasa Utara yang menyatakan bahwa: "Besarnya retribusi daerah yang harus dibayar oleh rumah sakit yang menggunakan jasa yang bersangkutan dihitung dari perkalian antara tarif dan tingkat penggunaan jasa dengan rumus sebagai berikut : Retribusi Terutang $=$ Tarif Retribusi $x$ Tingkat Penggunaan Jasa" (Sekretaris Bagian Accounting Badan Keuangan Kabupaten Minahasa Utara).

Tata Cara Penyetoran Retribusi Pelayanan Kesehatan. Dari hasil wawancara, Kepala Bagian Accounting Badan Keuangan Kabupaten Minahasa Utara menginformasikan bahwa: "Penyetoran retribusi pelayanan kesehatan dilakukan paling lambat 1 x 24 jam sejak penerimaan diterima. Dalam hal pembayaran yang diterima oleh Bendahara Badan Keuangan Pemerintah Kabupaten Minahasa Utara. Penerimaan pada saat diluar jam kerja atau pada waktu libur, penyetoran dilakukan paling lambat pada hari kerja berikutnya".

\section{KESIMPULAN DAN SARAN}

\subsection{Kesimpulan}

1. Retribusi pelayanan kesehatan di Kabupaten Minahasa Utara dengan tarif retribusi pelayanan kesehatan yang dipakai sesuai dengan PERDA Provinsi Sulawesi Utara Nomor 2 tahun 2012. Retribusi pelayanan kesehatan di pungut dengan menggunakan SKRD atau dokumen lain yang di persamakan. Retribusi daerah dihitung berdasarkan tarif retribusi dan tingkat penggunaan jasa. Tingkat penggunaan jasa di ukur berdasarkan jenis pelayanan.

2. Penerimaan retribusi pelayanan kesehatan di Kabupaten Minahasa Utara mulai dari tahun 2014 yang tingkat efektivitasnya hanya 30\% yang artinya tidak efektif. Pada tahun berikutnya 2015 mengalami peningkatan yang jauh lebih tinggi dari tahun sebelumnya yaitu sebesar 110,53\% artinya sangat efektif. Namun di tahun 2016 mengalami penurunan menjadi $107 \%$ meskipun begitu masih tergolong sangat efektif karena targetnya melampaui batas target. Hingga di tahun 2017 masih tetap sama yaitu 107\%.

3. Kontribusi sangat kurang. Dimana pada tahun 2014 kontribusi retribusi pelayanan kesehatan terhadap pendapatan asli daerah sebesar $1,47 \%$ dan pada tahun 2015 mengalami peningkatan yaitu 3,44\%. Pada tahun 2016 kontribusi nya sebesar 6,22\% dan pada tahun 2017 meningkat lagi menjadi 10\%.

\subsection{Saran}

1. Kepala Dinas Kesehatan lebih memperhatikan lagi kinerja staf.

2. Dinas Pendapatan Asli daerah agar lebih memperhatikan dan mengusahakan agar rumahrumah sakit yang berada di Kabupaten Minahasa Utara untuk membayar retribusi sesuai dengan tarif yang telah di tetapkan pemerintah. 
3. Upaya dalam melaksanan penagihan harus lebih diidentifikasi agar supaya target retribusi yang ditetapkan bisa terealisasi dengan baik.

4. Bagi peneliti selanjutnya diharapkan dapat memperluas dan mengembangkan ruang lingkup penelitian.

\section{DAFTAR PUSTAKA}

Adriani. 2013. Dasar-dasar Perpajakan. Penerbit Pustaka Universitas Terbuka. Jakarta.

Abdullah, Rozali. 2002. Pelaksanaan Otonomi Luas dan Isu Federalisme Sebagai Suatu Alternatif. Jakarta. PT. Raja Grafindo Persada.

Agustini. 2017. Efektifitas dan Kontribusi Pelayanan Kesehatan Terhadap Pendapatan Asli Daerah di Kabupaten Tanah Laut. Universitas Lambung Mangkurat.

Anggraeni, Dina. 2010. Analisis Pengaruh Penerimaan Pajak Daerah dan Retribusi Daerah Terhadap Peningkatan Pendapatan Asli Daerah Provinsi Bengkulu. Skripsi Jurusan Akuntansi. Universitas Islam Negeri Syarif Hidayatullah.

Chici, Juriko. Grace B. Nangoi. Sonny Pangerapan. 2017. Analisis Efektivitas dan Kontribusi Pajak Bumi dan Bangunan Perdesaan dan Perkotaan (PBB-P2) Sebagai Sumber Pendapatan Asli Daerah Kabupaten Minahasa, Minahasa Utara, dan Kota Manado. Jurnal Riset Akuntansi Going Concern 12 (2). Fakultas Ekonomi dan Bisnis Universitas Sam Ratulangi.

Darwin. 2017. Pajak Daerah dan Retribusi Daerah. Jakarta.

Ghozali, Imam. 2017. Analisis Kontribusi Retribusi Parkir dan Retribusi Pasar Terhadap Pendapatan Asli Daerah. Skripsi Fakulltas Ekonomi. Univesitas Muhammadiyah Ponorogo.

Hery. 2014. Akuntansi Perpajakan. PT.Grasindo. Jakarta.

Lubis, Irsan. 2015. Mahir Akuntansi Pajak Terapan. Berbasis Standard Akuntansi dan Ketentuan Pajak Terbaru. Andi. Yogyakarta.

Mardiasmo. 2009. Perpajakan. Penerbit Andi, Yogyakarta.

Mardiasmo. 2016. Perpajakan. Edisi Terbaru 2016. Andi, Yogyakarta.

Mamesa. 1995. Sistem Administrasi Keuangan Daerah. Pustaka Utama.

Republik Indonesia, Peraturan Pemerintah No. 58 Tahun 2005 Tentang Pengelolaan Keuangan Daerah.

Sari, Diana. 2013. Konsep Dasar Perpajakan.Cetakan Kesatu. Refika Aditama. Bandung.

Sumarsan, Thomas. 2013. Perpajakan Indonesia.: Pedoman Perpajakan Indonesia Lengkap Berdasarkan Undang - Undang Terbaru. Jakarta.

Subekti, Wibowo. 2012. Akuntansi Perpajakan. Salemba Empat. Jakarta.

Sugiyono. 2014. Metode Penelitian Pendidikan Pendekatan Kuantitatif, Kualitatif dan

$R \& D$. bandung : Alfabeta

Supradi. 2013. Aplikasi Statistika dalam Penelitian Konsep Statistika yang Lebih

Komprehensif. Jakarta Selatan: Change Publication

Supramono dan Theresia. 2015. Perpajakan Indonesia: Mekanisme dan Perhitungan. Andi, Yogyakarta.

Supriyanto, Eddy. 2011. Akuntansi Perpajakan. Edisi Pertama. Graha Ilmu,Yogyakarta.

Undang-undang Republik Indonesia Nomor 19 Tahun 2000 tentang Ketentuan Umum dan Tata Cara Perpajakan.

Undang-undang Republik Indonesia Nomor 28 Tahun 2007 tentang Ketentuan Umum dan

Tata Cara Perpajakan.

Undang -undang Republik Indonesia Nomor 28 Tahun 2009 tentang Pajak dan Retribusi Daerah. 
Undang -undang Republik Indonesia Nomor 34 Tahun 2000 tentang Pajak Daerah dan Retribusi Daerah.

Undang -undang Republik Indonesia Nomor 32 Tahun 2004 tentang Pemerintah Daerah Undang-undang Republik Indonesia Nomor 33 Tahun 2004 tentang Perimbangan Keuangan Antara Pemerintah Pusat dan Pemerintah Daerah.

Tjokroamidojo, Bintoro. 1984. Pengantar Administrasi Pembangunan. Jakarta. LP3ES.

TMBooks. 2015. Cermat Menguasai Seluk-Beluk Perpajakan Indonesia. Andi.Yogyakarta.

Widyaningsih, 2013. Hukum Pajakdan Perpajakan. Alfabeta. Bandung.

Warsito, 2001. Hukum Pajak. Jakarta. PT. Rajawali Grafindo Persada.

Waluyo, 2011. Perpajakan Indonesia. Salemba Empat. Jakarta.

Waluyo, 2013. Perpajakan Indonesia. Salemba Empat. Jakarta. 